\title{
Dynamic study of calcium phosphate formation on porous HA/TCP ceramics
}

\author{
Y. Duan $\cdot$ Z. Zhang $\cdot$ C. Wang $\cdot$ J. Chen $\cdot$ \\ X. Zhang
}

Published online: 15 August 2008

(C) Springer Science+Business Media, LLC 2008

\section{Erratum to: J Mater Sci: Mater Med \\ DOI 10.1007/s10856-004-5673-0, 10.1007/s10856-005-3577-2}

This article was mistakenly published twice, both in print and online. The publication details are as follows:

DOI 10.1007/s10856-004-5673-0 was published in volume 15, number 11, November 2004, pages 1205-1211.
DOI 10.1007/s10856-005-3577-2 was published in volume 16, number 9, September 2005, pages 795-801.

The official publication date of this article is that associated with DOI 10.1007/s10856-004-5673-0: November 2004. This was a Publisher's error.

The online version of the original article can be found under doi:10.1007/s10856-004-5673-0, 10.1007/s10856-005-3577-2.

\section{Y. Duan $(\bowtie)$}

State Key Laboratory for Modification of Chemical Fibers and Polymer Material, College of Material Science and Engineering, Donghua Univerisity, Shanghai 200051, People's Republic of China

e-mail: yrduan@dhu.edu.cn

\section{Z. Zhang}

West China School of Pharmacy, Sichuan Univeristy,

Chengdu 610041, People's Republic of China

C. Wang $\cdot$ X. Zhang

Engineering Research Center in Biomaterials, Sichuan

University, Chengdu 610064, People's Republic of China

J. Chen

Engineering Research Center in Biomaterials, Sichuan

University, Chengdu 610064, People's Republic of China 